\title{
WHAT HAS THE STATE AGRICULTURAL EXPERIMENT STATION AT HOORN CONTRIBUTED TO RESEARCH INTO THE FEEDING VALUE OF ROUGHAGE ? ${ }^{1}$ ]
}

\author{
N. D. DIJKSTRA \\ State Agricultural Experiment Station at Hoorn
}

\section{INTRODUCTION}

It was not until the spring of 1932 , when it became possible to make digestion trials at the State Agricultural Experiment Station at Hoorn, that determination of the feeding value of roughage could be studied intensively there.

The problems attending such calculations for roughage are quite different from those for concentrated feeding stuffs (concentrates). Since in the case of a concentrate, digestibility is almost independent of composition, one set of digestion coefficients will suffice for each type of concentrate. Accordingly, once this set has been established, one analysis only is enough, and the feeding value can then be calculated by means of the usual digestion coefficients.

However, in roughage, as is known, chemical composition is very much dependent on the stage of growth. The most important changes with age are a decrease in the content of crude protein and an increase in the content of crude fibre. These changes in chemical composition are, however, accompanied by great changes in digestibility, a result of which is that one set of digestion coefficients is not sufficient.

It was therefore a stroke of insight from the then Director of the Physiological Department of the State Agricultural Experiment Station at Hoorn, Professor Brouwer, to perceive that, if more knowledge of the feeding value of roughage is desired, digestion trials with the use of animals are indispensable.

\section{a Determination of digestibility}

The principle on which determinations of digestibility are based is a very simple one. All that is necessary is to ascertain the quantities of dry matter and other components eaten by an animal in a certain period, and also the quantities thereof excreted in the faeces during the same time. If, for example, a sheep receives 200 grams of crude protein per day in a ration of hay, and excretes 80 grams of crude protein in the faeces, 120 grams of crude protein will have been resorbed by the intestinal wall, or, in other words, this sheep digests 120 of the 200 grams of crude protein - or, $60 \%$. The digestion coefficient of the crude protein of this lot of hay will therefore be 60. The digestion coefficients of the other components can be calculated in the same way.

Accordingly, the difficulty lies not in the principle on which these trials are based, but in their technical execution. Care must be taken, for instance, to ensure that each of the animals receives the same quantity of the same feed each day. In order to achieve this result the roughage must be chopped and then mixed homogeneously. This homogeneous mixing is liable to present difficulties in the case of dry materials such as hay and dried grass, because the finest material sinks to the bottom. So, in order to eliminate this source of error, special precautions must be taken, such as sifting in fractions, etc.

Fresh material presents quite different problems. Variations in weather conditions may cause the dry matter content of such roughages to fluctuate considerably from one day to another. In order, notwithstanding, to be able to provide the animals with the same quantity of dry matter each day, it will be necessary to determine at once the content of dry matter in the roughage, so as to obtain data, on the basis of which the quantity of roughage administered can be varied from day to day.

\section{$b$ Choice of the trial animals}

For the first digestion trials at Hoorn bulls were used, out of consideration that the results had to be applicable to cows. Digestion trials on bulls have, however, certain drawbacks, such as the large amount of material which is needed for them, difficulties in the homogeneous mixing of the feed, in the quantitative collection of the faeces and in the homogenization of this great quantity of faeces so as to enable a good sample to be taken from it, etc.

\footnotetext{
1) Received for publication June 24, 1954.
} 
The bulls were therefore soon replaced by wethers (castrated rams) - a replacement productive of many advantages. These animals eat much less fodder, the faeces are easy to collect, and in most cases it is very easy to mix homogeneously.

Such advantages amply counterbalance the (primarily theoretical) objection that results thus found by experiments on sheep have to be applied, in practice, to cows. For it has been definitely established, from the results of many trials carried out abroad, and also from some of our own, that the digestive capacities of sheep and cow differ, generally speaking, very little from each other.

Each digestion trial carried out at Hoorn was performed on three animals, to ensure that a duplicate determination at any rate would be left if later on should be found that one of the wethers had digested the material unsatisfactorily, and that, in consequence, the data obtained from it had to be rejected (a rare occurrence).

\section{c Chemical analysis}

When weighing feeds destined for use in the digestibility trial, samples are taken for chemical analysis. In these samples, the contents of the following components will be determined: moisture, ash, crude protein and crude fibre. By adding up the percentages of these components, and subtracting the total from 100, the percentage of $\mathrm{N}$-free extract is obtained.

At Hoorn the fat content of roughage is not determined; it is simply classed among $\mathrm{N}$-free extract. This is done because the matter obtained in an ordinary fat determination (i.e., by extraction with ether) consists only partly of genuine fat. It consists of vegetable components, plant pigments such as xanthophyll, chlorophyll, etc., which likewise dissolve in ether. Not to have to determine the fat content signifies a considerable simplification of the analysis. Determination of true protein is also considered not to be necessary. The difference between $\mathrm{cp}$ and $\mathrm{tp}$ is formed by what are called "amides". These can be conceived as intermediate products between the simple nitrogen compounds assimilated by the plant, such as nitrate and ammonia, and true protein. In case of decomposition of protein, for instance by bacteria, amides are also, as a rule, the first products to arise. They were formerly regarded as practically valueless. Nowadays, however, most experts are of the opinion that they definitely possess protein and feeding value - at any rate, those amides found in roughages such as fresh and preserved grass.

The analyses are carried out on material which has been subjected to preliminary drying (known as air-dry material), and the figures found are converted into terms of the dry matter by reference to the moisture content of the sample.

Experiments are then carried out with the use of animals, to determine the digestibility of the source material from which the samples have been taken.

After that, the percentages of digestible components can be calculated from the analyses of the different samples, by means of the digestion coefficients ascertained.

Names of the components of feeding stuffs, with abbreviations.

$$
\text { Name Abbreviation }
$$

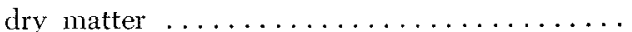

$\mathrm{dm}$

digestible dry matter $\ldots \ldots \ldots \ldots \ldots \ldots \ldots$ : $\mathrm{ddm}$

organic matter $\ldots \ldots \ldots \ldots \ldots \ldots \ldots \ldots$ om

digestible organic matter $\ldots \ldots \ldots \ldots \ldots \ldots$ dom

crude protein $\ldots \ldots \ldots \ldots \ldots \ldots \ldots \ldots \ldots \ldots \ldots, \quad \mathrm{cp}$

digestible crude protein :

determined with use of animals ...... dcp

determined by means of pepsin ...... dep (pepsin)

true protein $\ldots \ldots \ldots \ldots \ldots \ldots \ldots \ldots \ldots$ tp

digestible true protein $\ldots \ldots \ldots \ldots \ldots \ldots \ldots \quad \mathrm{dtp}$

fat $\ldots \ldots \ldots \ldots \ldots \ldots \ldots \ldots \ldots \ldots \ldots \ldots$ fat

digestible fat $\ldots \ldots \ldots \ldots \ldots \ldots \ldots \ldots$ dfat

crude fibre $\ldots \ldots \ldots \ldots \ldots \ldots \ldots \ldots \ldots$ of

digestible crude fibre $\ldots \ldots \ldots \ldots \ldots \ldots$ def

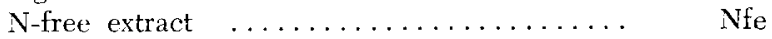

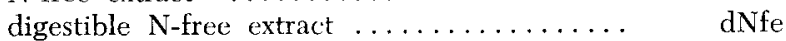

starch equivalent $\ldots \ldots \ldots \ldots \ldots \ldots \ldots . . \ldots \ldots$

fodder units $\ldots \ldots \ldots \ldots \ldots \ldots \ldots \ldots \ldots \ldots \ldots \ldots$ 


\section{$d$ The method of calculating the feeding value}

If the content of minerals and vitamins - which, as is known, are also of extremely great importance - is left out of consideration, the feeding value of a feeding stuff will be mainly determined by its content of dcp, and by its SE.

The conception of starch equivalent was introduced by Keldner. He expressed the value of a feeding stuff in terms of its fat-forming capacity. The unit of measurement he chose for this purpose was the quantity of fat which can be produced from $1 \mathrm{~kg}$ of digestible starch. Now, all the digestible organic components of a feeding stuff may contribute towards forming fat; consequently, all digestible organic components possess a certain SE. This is not equally high in the case of all components. According to Kellner

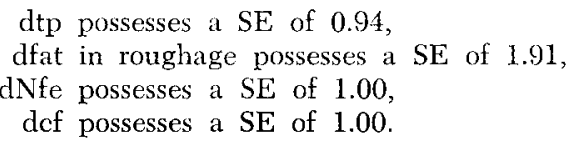

The fat-forming capacity of various feeding stuffs, i.e. the $\mathrm{SE}$, was determined by KELLNER by the use of animals. In doing so he found that the SE of certain fodders, empirically determined in this way, did not correspond to the SE found by computation, i.e. by adding up the values for the various components. In the great majority of cases, the value found empirically was lower. The richer the feed is in crude fibre, the greater the difference between the two values becomes. The reason for this is that the data used in carrying out the theoretical computation relate to the components in a pure state, whereas, in reality, these digestible components first have to be extracted from the feed concerned. From this it is also evident that the more of the fodder contains, the greater the difference will be. The more of there is, the thicker the cell walls, which have to be rendered permeable in order to make the cell contents free for digestion. In addition, more chewing effort is necessary to render such material fine, and, furthermore, transport of the undigested components through the intestines must also be taken into consideration, for the energy required to do this, is, naturally, no longer available for production purposes.

If the real fat-forming capacity of a feeding stuff - i.e., the SE determined by the use of animals - is expressed as a percentage of the theoretical SE obtained by adding up the starch equivalents of the separate components, the resulting number is called the "value number". Accordingly, if the "value number" of a fodder is 80 , its real fat-forming capacity will be $80 \%$ of the computed value. This "value number" is used, inter alia, for the various concentrates.

As regards roughages, KELLNER gives another method of obtaining the real SE from the computed SE. For this purpose he suggests that a certain amount should be deducted from the SE for each percent of crude fibre in it. In the case of hay and straw, this amount is $0.58 \mathrm{~kg} \mathrm{SE}$ per percent of ; in the case of fresh forage crops with less than $4 \% \mathrm{cf}$, it is $0.29 \mathrm{~kg} \mathrm{SE}$. This cf-deduction gradually increases from $0.29 \mathrm{~kg}$ in the case of $4 \%$ ef to $0.58 \mathrm{~kg}$ in roughages with $16 \%$ or more ef.

Accordingly, in this way Kellnen arrives at a SE in, for example, the case of hay, of :

$$
\mathrm{SE}=0.94 \mathrm{dtp}+1.91 \mathrm{dfat}+1.00 \mathrm{dNfe}+1.00 \mathrm{def}-0.58 \mathrm{cf} \text {. }
$$

At Hoorn a simplified method of calculating SE is always applied for roughages such as hay and suchlike. As has been said, the fat content is not determined separately, but is included among the $\mathrm{N}$-free extract.

Accordingly, digestible fat is multiplied by 1.00 instead of by 1.91 , and, owing to this, the SE will be rather too low. This, however, is corrected at Hoorn by carrying out calculations with dcp instead of with dtp - which causes the starch equivalent to be somewhat higher, so that the final result is almost the same. Thus, by applying this simplified method, not only determination of fat, but also determination of tp, can be dispensed with.

By the above mentioned method, we therefore obtain :

$$
\mathrm{SE}=0.94 \mathrm{dcp}+1.00 \mathrm{dNfe} \text { (fat included) }+1.00 \mathrm{dcf}-0.58 \mathrm{cf} \text {. }
$$

$\mathrm{Dcp}+\mathrm{dNfe}+$ dcf together form the digestible organic matter. Accordingly, the following can also be written for SE :

$$
\mathrm{SE}=\mathrm{dom}-0.06 \mathrm{dcp}-0.58 \mathrm{cf} \text {. }
$$

The starch cquivalent is therefore equal to dom on which two corrections have been applied, viz., a small one for dcp and a larger for cf. 
In this way it is possible to calculate the feeding value of any ronghage the digestibility of which has been determined by experiments on animals.

\section{$e$ Practical estimation of the feeding value}

In practice, however, it is not possible to carry out a digestion trial on every roughage sample. And nevertheless it is of great importance that farmers should be as well informed as possible regarding the feeding value of the roughages at their disposal during the winterseason. With this object in view, the Bedrifflaboratorium voor Gewasonderzoek (Practical Laboratory for Crop Testing) was established, as a section of the Chemical Laboratory of the C.I.L.O. (Central Institute for Agricultural Research) at Wageningen, in order to increase the possibilities for analyses of home grown roughages, such as hay, dricd grass, grass silage, etc.

Thesc analyses will take place on an even larger scale in the future. Practical laboratories for crop testing have already been established by the Stichting voor de Landbouw (Agricultural Foundation) in a number of places in the Netherlands, viz., Groningen, Oosterbeek, Goes and Geldrop, for the purpose of taking such analyses over from the C.I.L.O.

In these laboratories, however, it is only possible to determine the chemical composition of the roughage-samples submitted. It is evident that a direct determination of the feeding value of all these samples with experimental animals, is impossible.

Accordingly, endeavours must be made to estimate the feeding value of the various kinds of roughages as well as possible from the results of these chemical analyses. For this reason we have tried to find principles, from the data at our disposal at Hoorn, by means of which it will be possible to estimate the feeding value of roughages of which only the chemical analysis is known.

We have therefore tried to determine whether, perhaps, a relationship exists between composition and feeding value. For if this should be the case, it might be possible to define the relationship in a formula, graph or table, and by means of that, the feeding value might be calculated of a sample of hay, dried grass, or grass silage the composition of which is known.

In the course of years a great many kinds of roughages have been examined at Hoorn for digestibility, with the use of animals. The overwhelming majority of these trials relate to that roughage which is the most important for the Netherlands, namely, grass, and to the preserved products obtained from it: hay, artificially dried grass and grass silage. Accordingly, only those experiments relating to grass and to grass products will be discussed in the following pages.

\section{EXPERIMENTS ON HAY}

The first investigation at Hoorn in which digestion trials played an important part concerned hay; the report on it was published under the title: Onderzoek naar de voederwaarde van Nederlandse hooisoorten enz. (Investigation of the feeding value of Dutch lots of hay, etc.) (Brouwer and Dijkstra, 1938).

As has already been said, the following components were determined in analysis : moisture, ash, cp, cf, and, indirectly, Nfe. Since moisture and ash do not produce energy, it was possible to achieve a further degree of simplification by provisionally converting everything into terms of om. Accordingly, the only remaining figures are those for $\mathrm{cp}$, cf and $\mathrm{Nfe}$; only the first two of these need be used in making calculations, because the content of $\mathrm{Nfe}$ is also completely determined, for on om-basis

$$
\mathrm{Nfe}=100-\mathrm{cp}-\mathrm{cf} \text {. }
$$

It was obvious to choose dcp and $\mathrm{SE}$ as estimates for the feeding value. However, since SE cannot be directly determined in the digestion trial, we took dep and dom instead. It is possible to calculate the SE subsequently from the dom, by applying the corrections previously mentioned.

When, at the conclusion of our first investigation of the feeding value of 276 
Dutch lots of hay, the relationship between chemical composition and feeding value was explored, we still had only nine sets of results of our own at our disposal. But abroad very many digestion trials had already been carried out on hay. And because the number of our own determinations was considered to be insufficient, the data obtained in foreign countries were also used in the calculations.

It was found that a close correlation existed between $\mathrm{cp}$ and dep. This relationship was plotted by a regression line in the case of both foreign and Dutch lots of hay.

As is known, the general formula of a straight line is $y=a x+b$, in which the regression coefficient $a$ gives the gradient of the line (the greater the regression coefficient, the steeper the course of the line), and the constant term $b$ determines whether the position of the line will be high or low.

It appeared that both the regression coefficient and the constant term for the Dutch lots of hay were considerably lower than those for the foreign lots. From this it follows that the "Dutch" regression line must necessarily lie lower, and run less steeply, than the average "foreign" line. This was probably due to the fact that some of the Dutch lots of hay had heated slightly, while it was not unlikely that some of the foreign hay lots had not been in a haystack at all.

Finally, a regression line was chosen. Judged on the basis of the still limited number of data from Hoorn, the variation in feeding value of well made and preserved hay, could be expressed best by:

$$
\mathrm{d}=0.705(\mathrm{x}-12)+6.24
$$

in which $\mathrm{d}=\mathrm{dcp}$ and $\mathrm{x}=\mathrm{cp}$, both converted into om.

It was, however, considered permissible to increase results by $10 \%$ in the case of excellent hay, hardly heated at all in the haystack.

It was also found that the relationship between dom and cf was better than that between dom and cp. Consequently, the content of dom could be more accurately calculated from the cf-content than from the cp-percentage.

In conclusion, the following regression line was calculated from data regarding 133 foreign and 9 Dutch lots of hay:

in which $\mathrm{z}=$ dom and $\mathrm{y}=\mathrm{cf}$, both in om.

$$
z=-0.686(y-38)+60.5
$$

By means of the relation mentioned before : $\mathrm{SE}=\mathrm{dom}-0.06 \mathrm{dcp}-0.58 \mathrm{cf}$, it was possible to calculate the following formula for the $\mathrm{SE}$ :

$$
\mathrm{S}=-1.256(\mathrm{y}-38)+38.28 \text {. }
$$

This formula proved not to work particularly well in practice. At the C.I.L.O. it was thought that the course of the regression line was too flat, so that the difference between good and bad lots of hay was underestimated. For that reason, when we had acquired rather more data of our own, we calculated from it a new regression line, which actually did run rather more steeply.

However, as time went on, the number of digestion trials with hay at Hoorn became so great that it seemed expedient once more to review the relationship between $\mathrm{cp}$ and dcp, and between SE and cf.

The relation between the $\mathrm{cp}$ and dep of the lots of hay examined at Hoorn is demonstrated in Fig. 1. On the horizontal axis $\mathrm{x}=\mathrm{cp}$ has been plotted, and on the vertical axis $d=d c p$. The dots relate to 41 normal lots of hay, 
$\operatorname{dep}(\%)$ in om

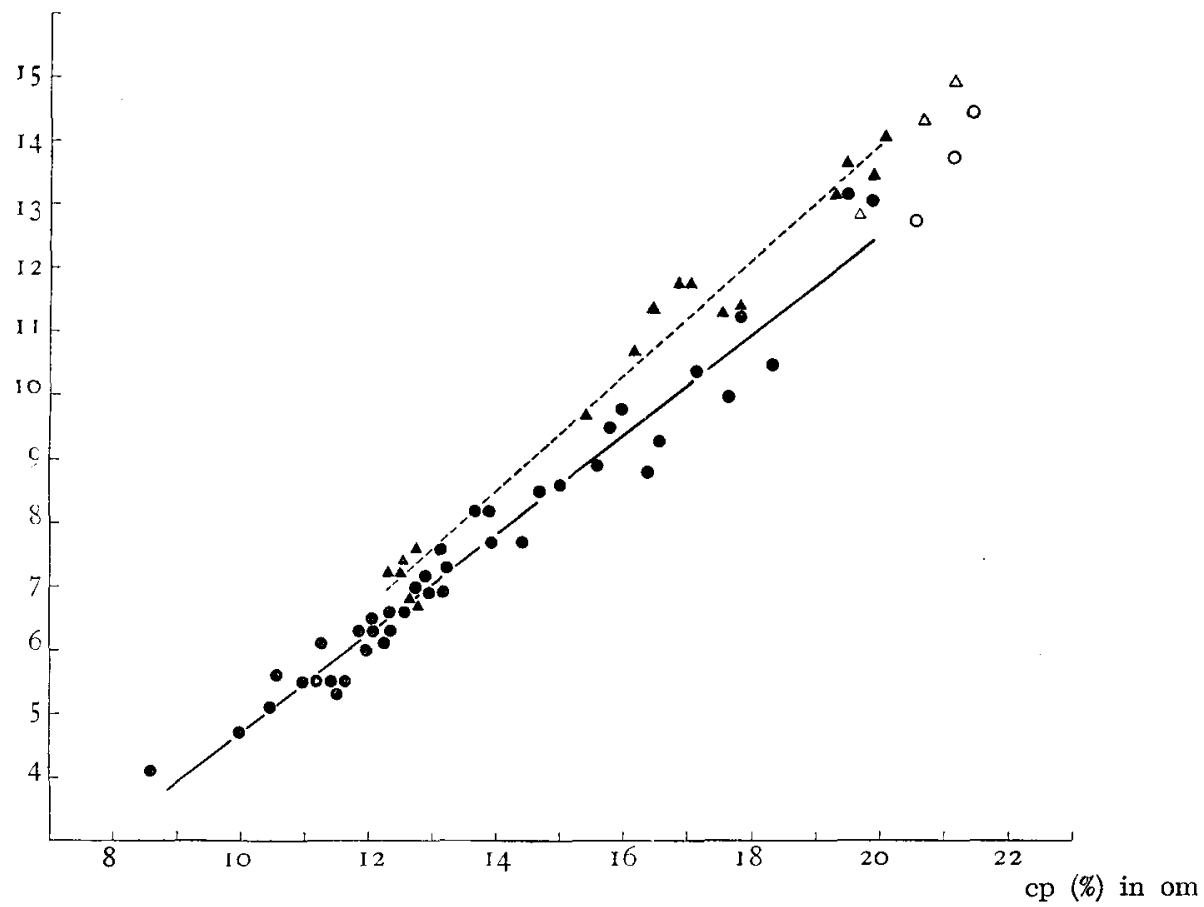

Fig. 1. Relation between CRUde protein (horizontal aXis) and digestible Crude protein (VERTICAL AXIS) IN 41 DIFFERENT LOTS OF HAY WHICH HAD BEEN STORED IN STACKS AND HAD HEATED LITTLE, IF AT ALL, (GERE REPRESENTED BY DOTS) AND 17 LOTS WHICH HAD NOT BEEN STORED IN STACKS (REIPRESENTED BY TRIANGLES).

which have fermented little or not in the haystack, and the 17 triangles relate to lots of hay before storage in the haystack. There are also 3 small circles and 3 open triangles, relating to autumn hay, before and after storage in the haystack. This number - six - was, however, too small to warrant a conclusion being drawn from it; and these lots of hay were therefore left out of the calculations.

The continuous line shows the relationship between $\mathrm{cp}$ and $\mathrm{dcp}$ in the lots of hay from the stack. The formula for this regression line is :

$$
\mathrm{d}=\mathbf{0 . 7 7 1}(\mathrm{x}-14)+\mathbf{7 . 7 6}
$$

Consequently, this line runs rather more steeply than that previously calculated.

In the case of the seventeen hay lots which were not stacked the regression line lies somewhat higher and runs even more steeply. The formula is:

$$
\mathrm{d}=0.890(\mathrm{x}-14)+8.46 \text {. }
$$

These formulas relate to the om. When the formula for hay that was stored in the stack is converted into terms of dry matter, for practical use, it becomes :

$$
\mathrm{d}^{\prime}=0.771\left(\mathrm{x}^{\prime}-13\right)+0.030\left(\mathrm{~m}^{\prime}-9\right)+7,265 \text {, }
$$

in which $\mathrm{d}^{\prime}=\mathrm{dcp}, \mathrm{x}^{\prime}=\mathrm{cp}$, and $\mathrm{m}^{\prime}=$ ash content, all in the $\mathrm{dm}$.

The coefficient 0.030 , placed in front of the term containing $\mathrm{m}^{\prime}$, is so small that this term has but little influence. In fact, if the ash content differs only slightly from 9 , the term may be omitted. 
The correlation between the of and dom of the same lots of hay is shown in Fig. 2. On the horizontal axis $y=$ cf has been plotted, and on the vertical axis $\mathrm{z}=$ dom. The dots, triangles, etc., have the same meaning as in the previous figure.

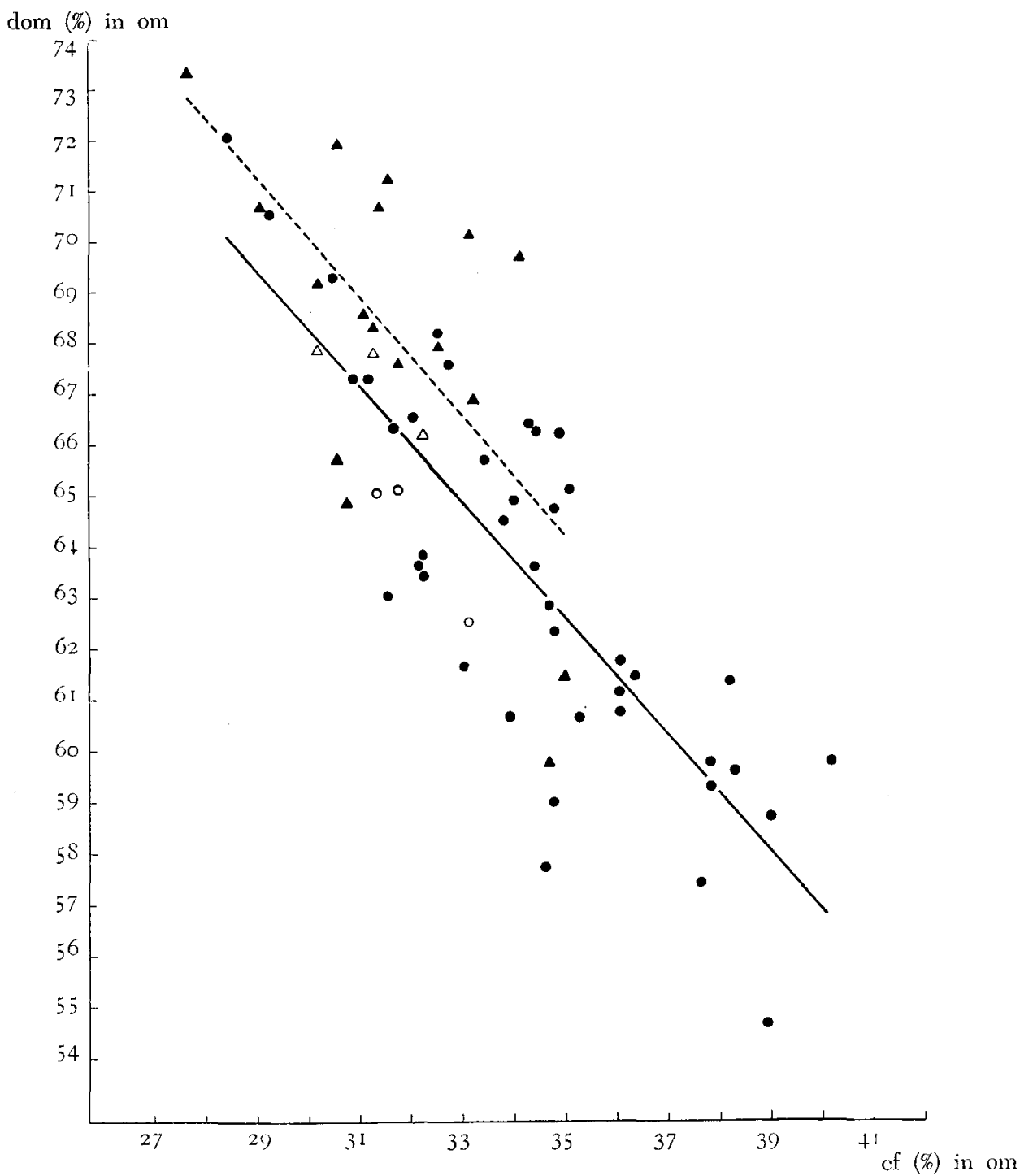

Fig. 2. Relation Between crude fibre (hokizontal aXis) AND Digestible organic MatTer (vertical aXIs) iN THE SAME LOTS OF haY as IN Fig. 1.

It can easily be seen from the diagram that a fairly good correlation exists between cf and dom, even if this correlation is less good than that between cp and dcp. In this, however, it is not necessary only to trust appearances ; it is also possible to establish the relation mathematically. The correlation between two quantities is usually indicated by means of correlation coefficients. The value of these coefficients can only fluctuate between -1 and +1 . In the case 
of values in the neighbourhood of -1 or +1 the correlation between the quantities is very good; in the case of values in the neighbourhood of 0 there is no correlation at all. The correlation coefficient between dom and cf was -0.81 ; consequently this indicates a rather good relationship (between cp and dep we found a correlation coefficient of 0.98 - i.e., an unusually high one -).

In Fig. 2, the continuous line indicates the relation between dom and of in the lots of hay stored in the haystack, i.e. the normal lots of hay. The formula for this regression line is :

$$
\mathrm{z}=-1.118(\mathrm{y}-35)+62.83
$$

in which $\mathrm{z}=$ dom and $\mathrm{y}=\mathrm{cf}$, both in om.

A broken line has also been drawn in the diagram. This indicates the relationship between dom and of in the 17 lots of hay which were not stacked. This line lies rather higher, and also follows a somewhat steeper course than the continuous line. The formula for this is :

$$
z=-1.165(y-35)+64.44 \text {. }
$$

The SE for the normal hay - i.e., hay after storage in the stack - can now be calculated again by use of :

$$
\mathrm{S}=\mathrm{dom}-0.06 \mathrm{dep}-0.58 \mathrm{cf}
$$

or, according to the notation used here: $\mathrm{S}=\mathrm{z}-0.06 \mathrm{~d}-0.58 \mathrm{y}$. Since $\mathrm{z}$ is already a function of $\mathrm{y}$, only $0.06 \mathrm{~d}$ still needs to be expressed in terms of $\mathrm{y}$.

In order to be able to do this, the relationship between dcp and of - or, in other words, between $\mathrm{d}$ and $\mathrm{y}$ - was examined in the 41 lots of hay mentioned above. The following regression line was calculated:

$$
\mathrm{d}=-0.527(\mathrm{y}-35)+7.20 \text {, }
$$

whereby the formula for the $\mathrm{SE}$. of normal hay becomes :

$$
S=-1.666(y-35)+42.10 \text {. }
$$

This formula relates to the om. If, for practical use, it is converted into terms of dry matter it becomes :

$$
S^{\prime}=-1.666\left(\mathrm{y}^{\prime}-32\right)-1.004\left(\mathrm{~m}^{\prime}-9\right)+38.06
$$

in which $\mathrm{S}^{\prime}=\mathrm{SE}, \mathrm{y}^{\prime}=$ of and $\mathrm{m}^{\prime}=$ ash content, all in the $\mathrm{dm}$.

As can be seen from these formulas the SE decreases by nearly 1.7 units for each per cent by which the cf content increases.

The feeding value of a lot of hay can therefore be estimated as well as possible, when only its chemical analysis is known, by means of the formulas for the dep and SE. In the experiments at Hoorn, we find this method, as a rule, inadequate, and in most cases a digestion trial of the hay is carried out, whereby its content of dcp and dom is accurately determined. From this, it is then possible to calculate the $\mathrm{SE}$; but we are not able to determine this value experimentally, since we have no respiration apparatus for ruminants at our disposal at Hoorn.

There is, however, a way of testing the calculated SE, i.e., by means of a feeding trial on milking cows.

As is generally known, content of cp decreases, and that of cf increases, as grass grows older. The fact that this chemical change is accompanied by a diminution in feeding value has likewise already been reported, and is also obvious from the formulas mentioned before. 
For, when the cp content decreases, the dcp content also decreases substantially, and an increase in cf content goes hand in hand with a considerable decline in SE. In consequence, there is a great difference in feeding value between early- and late-cut hay.

With the intention of confirming this, a feeding trial on milking cows was made at Hoorn in the winter of 1936-'37 (Brouwer and Dijkstra, 1939). The main purpose of the trial, however, was to examine the extent of the possible saving in concentrates by feeding cattle with early-cut hay in comparison with late-cut hay. It would be easy to draw conclusions if cows were to eat equal amounts of both kinds of hay; but this needs not necessarily be the case. If, for example, a smaller amount of the more nutritious early-cut hay would be eaten than of the less nutritious late-cut hay, this would do much to counterbalance the saving in concentrates, or would perhaps cancel it out altogether.

If, on the other hand, a greater quantity of the more nutritious hay was to be eaten than of the poorer kind, a double advantage would result. The cows fed on more nutritious hay would have an advantage for two reasons: firstly, because they receive hay with a higher feeding value, and secondly because they eat a greater quantity of that more nutritious hay. Consequently, in this case it would be possible to cut down the supply of concentrates more drastically.

The early-cut hay was mown on 26th May, and the late-cut hay on 16th June, i.e. three weeks later. The feeding trial was made with two groups of 13 milking cows, which had calved in October or in the first half of November. The trial was divided into three periods, viz. a preliminary control-period, the experimental-period, and afterwards a second control-period. In the first and second control-period, both groups received exactly the same feed; only in the experimental-period, which lasted eight weeks, did each group receive different feed. In that period the cows of group I received early-cut hay, and those in group II received late-cut hay.

In this trial all cows received as much hay as they would eat and at the same time the quantity of concentrates was diminished in such a way that the total amount of starch equivalent for each cow did not alter. In doing this it was found that group I consumed in the experimental-period $12.98 \mathrm{~kg}$ of early-cut hay, in addition to $2.86 \mathrm{~kg}$ of concentrates and $9 \mathrm{~kg}$ of grass-silage, on an average, per cow per day, and that group II consumed $11.15 \mathrm{~kg}$ of latecut hay $+4.41 \mathrm{~kg}$ of concentrates and likewise $9 \mathrm{~kg}$ of silage. So it appeared that a greater quantity of the more nutritious, early-cut hay could be eaten than of the coarser, inferior hay. The result of this was that the animals in group I, who received the early-cut hay, received an average of $1.55 \mathrm{~kg}$ of concentrates less per animal per day than the cows in group II, which were fed on late-cut hay.

In spite of this, the milk and fat production of the two groups were practically the same, whereas there was also practically no difference in live weight and condition.

This trial therefore shows that it is possible to save $1 \frac{1}{2} \mathrm{~kg}$ of concentrates per cow per day in the ration of milking cows by cutting the hay early instead of late.

This is about all the experiment station at Hoorn has contributed in the course of years to research on the feeding value of hay. There remains to be 
mentioned an inquiry that was made in the winters of 1937-'38 and 1938-'39 into the carotene content of hay from a number of farms in Friesland, North Holland and Limburg (Brouwer and Dijkstra, 1941).

In general, the hay from Friesland and North Holland then proved to possess very low contents of carotene - in the first winter, an average of only $2.0 \mathrm{mg}$, and in the second year an average of $3.9 \mathrm{mg}$, per kilogram of hay. The carotene contents of the Limburg hay proved to be definitely higher. In the case of this type of hay, average carotene contents of 7.3 and $13.9 \mathrm{mg}$ per $\mathrm{kg}$ hay were found, for the two seasons respectively - a result which will be largely owing to the fact that Limburg hay does not heat so much in storage.

The North Holland and Friesian hay is frequently so deficient in carotene that supplying even a substantial quantity of hay is insufficient to satisfy the carotene requirements of dry cows. In Limburg the situation is much more favourable, although even there the hay is not always able of satisfying the needs of cows in full lactation, least of all if the quantity supplied is but small. It is therefore recommendable, in many cases, to supplement the cows' ration by other feeding stuffs containing carotene.

\section{TRIALS WITH FRESH AND ARTIFICIALLY DRIED GRASS}

The second investigation at Hoom in which digestion trials played an important part related to fresh grass. The report on it was published under the title: Over de verteerbaarheid en voederwaarde van vers gras, gemaaid in verschillende groeistadia (The digestibility and feeding value of fresh grass cut at various stages of growth) (Dijkstra and BrouwEr, 1938, 1939).

A start was made with cutting the fresh spring grass for the digestion trials as soon as cutting was possible, and this continued until the grass became coarse and lodged. As regards chemical composition, it was confirmed that, as the grass grows older, its percentage of $\mathrm{cp}$ in the dm decreases, and its percentage of ef increases. The decline in protein content did not proceed regularly; at first it was very pronounced (as much as $3 \%$ in the first week), and later became much less. Also in this experiment was found that the digestibility of the grass decreases as the crop grows. The digestion coefficients of the cp dropped fairly regularly from 75.8 to 57.6 in seven weeks, i.e. by an average of $2.6 \%$ per week. The digestion coefficients of the om fell from 77.6 to 61.9 in that time, i.e. by an average of $2.2 \%$ per week. However, this drop did not take place regularly; in the first weeks it was very small, but later it increased considerably.

It was possible to calculate the feeding value of the various grass samples by means of the digestion coefficients found. The SE-calculation was carried out in the same way as in hay, the only difference being that the deduction for crude fibre was 0.29 instead of 0.58 . The formula is therefore:

$$
\mathrm{S}=\mathrm{dom}-0.06 \mathrm{dcp}-0.29 \mathrm{cf} \text {. }
$$

At that time (1938) the lots of grass investigated for digestibility were examined to see if there was in this material too a relation between $\mathrm{cp}$ and dcp, and between of and dom. The results obtained at Hoorn (only 13) were not considered numerous enough for this purpose, and accordingly results obtained abroad (in all, 148) were also utilized.

Here again, the analyses were first converted into terms of om.

It was found that there was a very good correlation between $\mathrm{cp}$ and $\mathrm{dcp}$ 
(correlation coefficient + 0.99). This high correlation coefficient shows that it is possible to calculate the content of dep accurately from the content of cp by means of a regression formula. This formula was as follows :

$$
\mathrm{d}=0.939(\mathrm{x}-20)+15.32 \text {. }
$$

The correlation between dom on the one hand, and $\mathrm{cp}$ and cf on the other, was much less pronounced. The correlation between dom and $\mathrm{cp}$ was about as good as that between dom and cf. But owing to the fact that the SE can be deduced from dom by applying, inter alia, a cf-deduction, the correlation between SE and cf is better than that between SE and cp. The SE was therefore calculated from the cf-content.

From the data available at that time - i.e., mainly foreign data - it appeared that it was not recommendable to use a straight regression line. A curve was then calculated, the formula of which was:

$$
\mathrm{S}=80.23-0.241 \mathrm{y}-0.287 \times 10^{0.0501 \mathrm{y}}
$$

It was disappointing to find that the standard deviation was still fairly considerable, even here. The SE and the dep-content of autumn grass were somewhat lower than would have appeared from calculations with the formula.

When, in 1938, artificial drying of grass started in some places in the Netherlands, this dried grass was also included in the Hoorn investigations, and was examined for digestibility with the use of sheep.

The first experiment (Brouwer and Dijкstra, 1938, 1939) refers to six lots of dried spring grass, and one lot of dried autumn grass. All were dried in a Hubert- Kaloroil drying plant.

The digestibility of this artificially dried grass was compared with that of fresh grass. The digestibility of the $\mathrm{cp}$ was found to be only a little lower than in fresh grass, viz., about $5 \%$. The digestibility of the other components proved not to have been diminished by the artificial drying. In consequence, there was no difference of any importance in dom content between dried and fresh grass and therefore for dom the fresh grass formula could be used. By applying a small correction, the dep content of artificially dried grass could be deduced from that of fresh grass.

But a difficulty arose in calculating the SE, namely - "how large must the cf-deduction be for artificially dried grass?" As is known, KELLNER recommended that for hay this deduction should be fixed at 0.58 per percent of ; for fresh grass, on the other hand, he recommended 0.29 . It would only have been possible to resolve this uncertainty by trials with a respiration apparatus, which, however, was not available to us.

Consequently, a choice of deduction had to be made; and we thought it best to take an average of the two values, namely 0.44 . The formula for the $\mathrm{SE}$ of dried grass thus differed from that of fresh grass only by the cf-deduction, that was 0.44 instead of 0.29 .

In artificially dried autumn grass, the feeding value was a little lower than had been calculated by means of the formula.

In 1943, in co-operation with the C.I.L.O., artificially dried grass of the first, third, and fifth cutting, from three fields of grass in the Utrecht-South Holland pasture region, were examined at Hoorn for digestibility (Dijkstra, 
1947, 1949). When the results of this trial were compared with the formulas evolved in 1938 it was found that, in some of the samples, the real digestibility of the protein lay substantially below the theoretical digestibility.

Since, as is known, the digestibility of protein is somewhat dependent on the drying temperature, it appeared to us not improbable that the method of drying might have played a part in this decline in digestibility.

That was the reason for carrying out a second trial at Hoorn - again, in co-operation with the C.I.L.O. - in which grass dried at different temperatures was examined for digestibility with the use of wethers.

This experiment refers to six lots of dried grass, dried partly at Woerden on a v.d. Broek dryer, and partly at Bodegraven on a Hubert-Kaloroil drying plant. The grass used as starting material was cut on 3rd September.

At Woerden drying was carried out at four different inlet temperatures, viz. $700^{\circ}, 550^{\circ}, 400^{\circ}$ and $250^{\circ} \mathrm{C}$, and at Bodegraven at two different inlet temperatures, viz. $200^{\circ}$ and $150^{\circ} \mathrm{C}$. The dcp-contents determined for this grass were lower than the theoretically calculated values for fresh grass. In the case of the three samples dried at the lowest temperatures, the difference was about $10 \%$; in the case of the other three lots, which were dried at temperatures of $400^{\circ} \mathrm{C}$ and more, the difference was much greater, and amounted to 25 to $29 \%$.

It could therefore be concluded from this that the digestibility of protein could considerably be reduced by drying at high temperatures.

With the intention of studying this important problem further, another trial was made in 1948, partly in South Holland and partly in Friesland (DijKsTra, 1950). In South Holland the same grass was dried by means of a Hubert, an Ensink and a v.d. Broek drying plant. In Friesland an other lot of grass was dried by using a Hubert, a Du Croo and Brauns, and a Templewood plant. These six lots of dried grass were also examined at Hoorn for digestibility. In the case of the grass from Friesland, dried at inlet temperatures varying from $135^{\circ}$ to $185^{\circ} \mathrm{C}$, the decline in digestibility of the protein was not very great; at the lowest temperature it was $3.7 \%$, and at the highest $8.4 \%$, i.e., almost the same as had been found in the first experiments. In South Holland, on the other hand, the decline in protein digestibility was considerably greater, varying from 13.6 to $19.3 \%$. Accordingly, it was also high in the case of grass dried with the Hubert-Kaloroil plant, which, however, functioned in South Holland at a higher inlet temperature $\left(200^{\circ} \mathrm{C}\right)$. However, the starting material used in South Holland was not the same as in Friesland, and this may have influenced the results.

It was therefore desired to repeat this experiment, of drying grass at different temperatures, but taking as starting material grass from the same field, dried in one day on various drying plants. This experiment was made in 1949, in co-operation with the C.I.L.O. and the Association of Co-operative Grass Dryers in Friesland. On 21st June a second-cutting grass from Leeuwarden airfield was dried on drying plants of six different types, the inlet temperatures varying from $140^{\circ}$ to $800^{\circ} \mathrm{C}$. At the lowest temperature the decline in digestibility was only $1 \%$; at higher temperatures it gradually increased; and at the highest temperature it amounted to $12.2 \%$. In all the experiments mentioned here a relation was found between temperature and the decline in digestibility of the protein. When, however, drying was carried out carefully 
at inlet temperatures below $200^{\circ} \mathrm{C}$, the decline was not great, and averaged about $5 \%$. But if drying was carried out at higher temperatures, the decline in protein digestibility could become very considerable, and sometimes amounted to $25 \%$.

Later trials have shown that the general arrangement and handling of the high-temperature driers in the Netherlands has been improved in the last years in such a way that, now, when drying grass, a product can be obtained, in which the decrease in digestibility of the protein is not higher than in the same grass dried in a low-temperature drier.

As has already been said, we had at our disposal very little data of our own in 1938, when formulas were calculated for estimating the feeding value of fresh and artificially dried grass from their chemical composition.

As the years went on, the number of trials at Hoorn gradually increased, so that in 1948 in total 62 digestion trials with fresh or artificially dried grass had been made there. In spite of the fact that some of these trials related to autumn grass, and that, moreover, some of the samples had been dried on aberrant types of driers, the number nevertheless seemed sufficient to allow the earlier formulas to be reconsidered.

As before, the analyses were converted into terms of om.

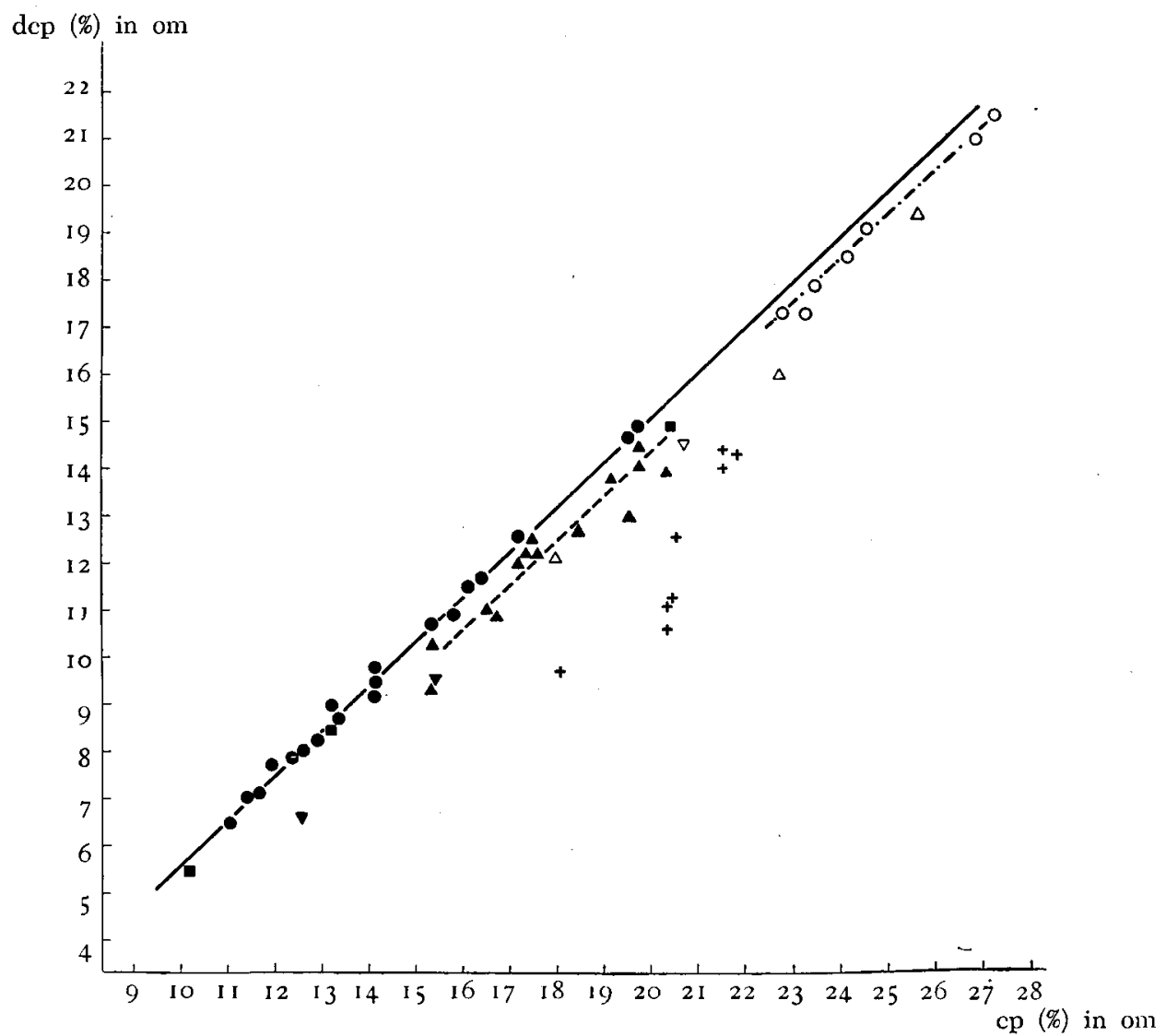

Fig. 3. Relation between crude protein (horizontal aXis) and digestible crude proteln (VERTICAL AXIS) IN 62 LOTS OF FRESH AND ARTIFICIALLY DRIED GRASS. 
In order to be able to study the relation between the cp- and dcp-contents of the various types of grass the cp-contents of these different lots of grass have been plotted on the horizontal axis of Fig. 3, and the dcp-contents have been plotted on the vertical axis.

In this graph the figures relating to fresh spring grass are represented by dots. These dots lie nearly on a straight line. Fig. 3 also includes three squares. These relate to grass dried at about $50^{\circ} \mathrm{C}$. From the location of the squares it can be seen that this drying has hardly decreased the digestibility of the protein. Again, in Fig. 3 the data from the samples of fresh autumn grass are indicated by small circles. In the case of this grass, too, the relation can be very well represented by a straight line; but the line lies below that of fresh spring grass. The data relating to grass dried at temperatures below $200^{\circ} \mathrm{C}$ are indicated by triangles. Open triangles are used to represent autumn grass, and blocked-in triangles to represent spring grass. Finally, 8 small crosses are also shown in Fig. 3, which relate to grass-meal, dried at higher temperatures. From the location of the crosses it can be seen that, in these samples, the dcp-content was much lower than might have been presumed from the cp-content.

In Fig. 3 three lines have been drawn. The continuous line relates to fresh spring grass; the dashed line to spring grass artificially dried at a relatively low temperature; and the line consisting of alternate dots and dashes gives the relation between $\mathrm{cp}$ and $\mathrm{dcp}$ in fresh autumn grass. Since, in the three relevant regression formulas, the regression coefficients differed but little from each other, one common regression coefficient has been calculated for all three. Owing to this, the three lines run parallel.

In this way, the following formula has been found for fresh spring grass :

$$
\mathbf{d}=0.948(\mathrm{x}-20)+15.13 \text {, }
$$

in which $\mathrm{x}$ represents $\mathrm{cp}$, and $\mathrm{d}$ represents $\mathrm{dcp}$. For fresh autumn grass, the following has been found :

$$
\mathrm{d}=\mathbf{0 . 9 4 8}(\mathrm{x}-20)+\mathbf{1 4 . 5 2} \text {. }
$$

This line lies $0.60 \%$ below the line for fresh spring grass. Finally the formula for spring grass dried at relatively low temperatures was:

$$
\mathrm{d}=\mathbf{0 . 9 4 8}(\mathrm{x}-20)+14.39 \text {. }
$$

This line lies $0.74 \%$ below the line for fresh spring grass.

If we give the formulas for $\mathrm{dm}$ instead of for om, we get, for the fresh spring grass :

$$
\mathrm{d}^{\prime}=0.948\left(\mathrm{x}^{\prime}-18\right)+0.038\left(\mathrm{~m}^{\prime}-10\right)+13,62 .
$$

The coefficient of the term containing $\mathrm{m}^{\prime}$ is so small that the term can be ignored, if $\mathrm{m}^{\prime}$ differs not too much from 10 . It is still better to apply the formula in which $\mathrm{m}^{\prime}$ has been eliminated. This simple formula is as follows:

$$
\mathrm{d}^{\prime}=0.954\left(\mathrm{x}^{\prime}-18\right)+13.62
$$

In this way, we find for fresh autumn grass :

$$
\mathrm{d}^{\prime}=0.955\left(\mathrm{x}^{\prime}-18\right)+13.07
$$

and for artificially dried grass :

$$
\mathrm{d}^{\prime}=0.955\left(\mathrm{x}^{\prime}-18\right)+12.96 .
$$

In 1948 , for the calculation of $\mathrm{SE}$, digestible protein-free om was taken as 
starting point instead of the dom, as formerly. The reason for this was a theoretical one. Artificial drying reduces the digestibility of $\mathrm{cp}$; but the digestibility of the of and Nfe - i.e., of the protein-free om - is not affected by it. Consequently, there is no difference between the digestible protein-free om in fresh and in artificially dried grass, and these lots of grass can therefore be regarded as one group. A good relation was found to exist between the cf-content and the digestible protein-free om, but this method of computation dom $(\%)$ in om

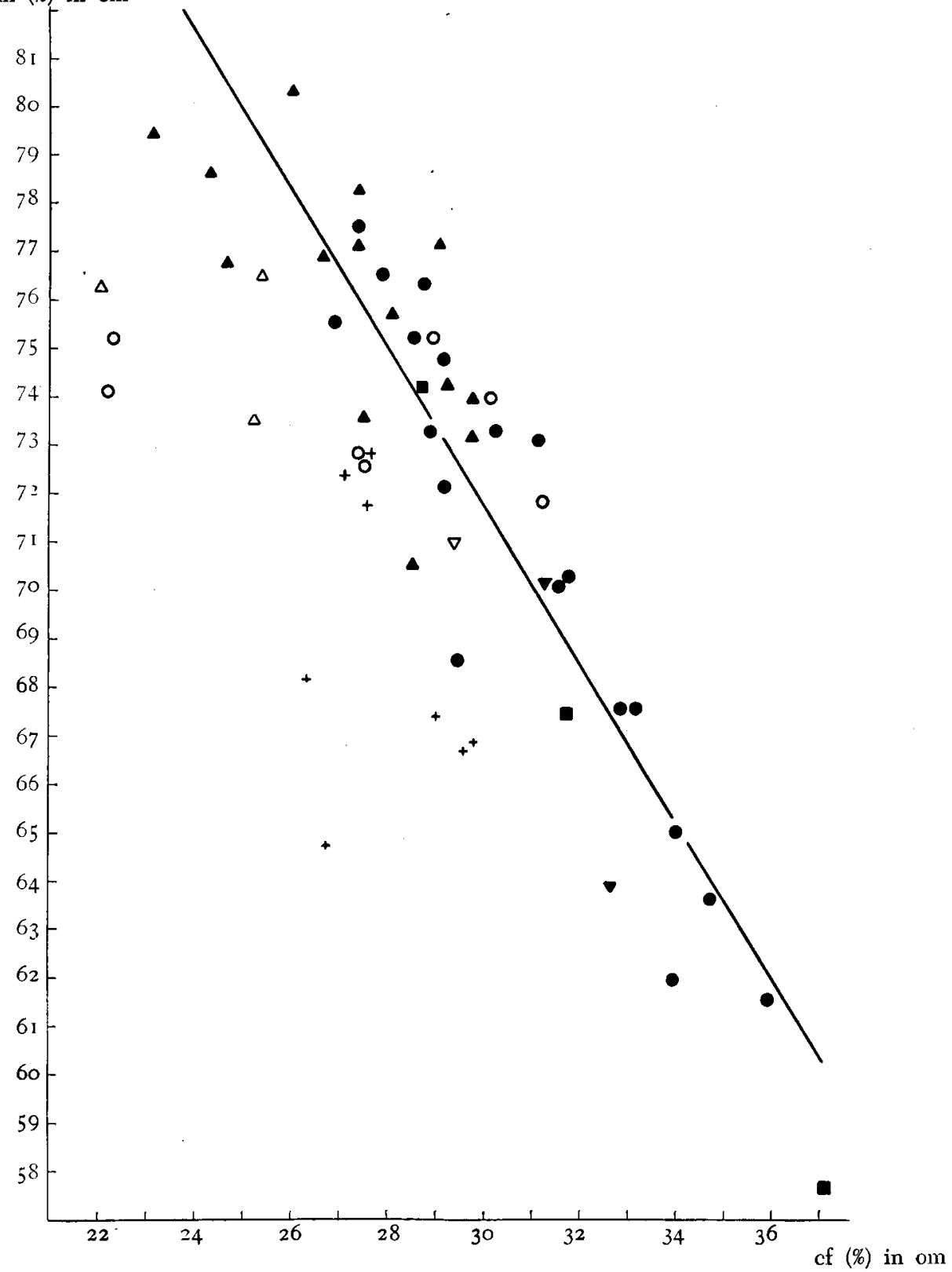

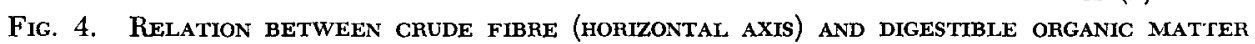
(vertical axis) In the Same lots of grass as in Fig. 3. 
had a drawback in that the final result was a formula for the SE which contained not only $\mathrm{y}$, but also $\mathrm{x}$, and even $\mathrm{xy}$, and was therefore rather complicated.

Therefore we returned to the dom. In Fig. 4 the cf-percentages have been plotted on the horizontal axis, and the dom-percentages on the vertical axis. The various symbols are the same as in Fig. 3.

In the case of the samples of spring grass, a close correlation was found between dom and cf. The relation is almost rectilinear between 25 and $37 \%$ cf in the om. Although it is very probable that digestibility increases much less quickly in the case of cf-percentages below $25 \%$, the amount of data available for this region was much too small to enable such a curve to be calculated with any degree of certainty.

Although in Fig. 4 there is no difference to be seen in the position of the dots and triangles, in theory, owing to a little lower digestibility of the $\mathrm{cp}$, the percentage of dom in artificially dried grass will inevitably be somewhat lower than in the corresponding fresh grass. Accordingly, parallel regression lines were calculated for the fresh grass and for the artificially dried grass.

In this way, for the fresh grass was found:

$$
\mathrm{z}=-1.600(\mathrm{y}-30)+71.97
$$

and for the artificially dried grass :

$$
\mathrm{z}=-1.600(\mathrm{y}-30)+71.84 \text {. }
$$

The difference amounts to only 0.13 and so is of no practical importance; consequently, fresh grass and grass dried at a low temperature are regarded as one group, in which the following regression was calculated between of and dom:

$$
\mathrm{z}=-1.588(\mathrm{y}-30)+71.92 .
$$

This line has been drawn in Fig. 4.

As has been said, we have derived for fresh grass :

$$
\mathrm{S}=\mathrm{z}-0.06 \mathrm{~d}-0.29 \mathrm{y} \text {. }
$$

Here too, d must again be expressed as a function of $y$. For fresh grass was found:

$$
\mathrm{d}=-0.563(\mathrm{y}-30)+10.38 \text {. }
$$

By means of this we calculated for the $\mathrm{SE}$ of fresh grass :

$$
\mathrm{S}=-1.844(\mathrm{y}-30)+62.60 \text {. }
$$

As regards dried grass, 0.44 was taken as cf-deduction factor, instead of 0.29 , and the formula then becomes:

$$
\mathrm{S}=-1.994(\mathrm{y}-30)+58.10
$$

For the practical use the formulas were again converted into terms of $\mathrm{dm}$. That for fresh grass became:

$$
\mathrm{S}^{\prime}=-1.844\left(\mathrm{y}^{\prime}-27\right)-1.179\left(\mathrm{~m}^{\prime}-10\right)+56.34
$$

and that for dried grass:

$$
\mathrm{S}^{\prime}=-1.994\left(\mathrm{y}^{\prime}-27\right)-1.179\left(\mathrm{~m}^{\prime}-10\right)+52.29
$$

As has been said, 0.44 was assumed as the factor for cf-deduction in artificially dried grass.

With the intention of testing the SE figures thus obtained, in the winter of 1938-'39 a feeding trial was made with two groups of 12 milking cows (Dijkstra, 1939). In this experiment we have examined to what extent the 
amount of concentrate in a ration containing only hay as roughage can be replaced by dried grass, and also to what extent the quantity of hay must be reduced in such a case.

The dried grass used in the first half of the experimental period contained $12.8 \% \mathrm{dcp}$ and had a SE of 55.7. The grass fed in the second half contained $10.4 \%$ dcp and had a SE of 61.4 , all in $\mathrm{dm}$. This second lot of grass therefore possessed a higher SE, and less dcp.

The quantity of dried grass given to the animals depended on their production, and consequently varied from one cow to another. However, none of them ever received more than $8 \mathrm{~kg}$. In the second half of the E.P. (experimental period), the grass, which was poorer in protein, had to be supplemented by concentrates rich in protein (peanut cake meal and soya bean cake meal).

On an average, in E.P. I $6.3 \mathrm{~kg}$ dried grass was compared with $5.0 \mathrm{~kg}$ hav $+1.9 \mathrm{~kg}$ concentrates and in E.P. II $5.4 \mathrm{~kg}$ dried grass $+0.9 \mathrm{~kg}$ concentrates rich in protein was compared with $3.1 \mathrm{~kg}$ hay $+3.3 \mathrm{~kg}$ concentrates, all per cow per day.

There was practically no difference in live weight and condition between the two groups. The milk production of the grass group was somewhat higher than that of the control group; the corrected difference amounted to $0.61 \mathrm{~kg}$ of milk per cow per day. The fat yield was practically the same in both groups.

On the whole, the figure of 0.44 for of-deduction seemed to have been a fairly accurate estimate. From the result of this trial it might be concluded, in view of the somewhat higher milk yield, that the cf-deduction of 0.44 was rather on the high than on the low side.

Furthermore, both the iodine value and the content of carotene and vitamin A of the butter were considerably higher in the grass group than in the control group, which very definitely signifies an advantage.

A second trial, in which the experimental ration contained a large quantity of dried grass, was made in the winter of 1941-'42 (Dijkstra, 1942, 1943). The intention of this trial was to study the effect on the production and condition of milking cows caused by feeding a ration of nothing but grassland products (hay, grass silage and dried grass), viz., without making use of concentrates.

In the E.P., each cow of the experimental group received $5 \mathrm{~kg}$ of hay per day, a substantial ration of a good grass silage, and as much grass-meal as it needed, according to the standards of Lars Frederiksen (Frederiksen and ØstergaARD, 1931) at any rate, when it had the capacity of eating such a large amount of roughage. In E.P. I, most of the animals received $24 \mathrm{~kg}$ of A.I.V. grass silage, four of them received $18-20 \mathrm{~kg}$ and one of them $13 \mathrm{~kg}$, while the quantity of grass-meal varied from 3.9 to $9.8 \mathrm{~kg}$, with an average of $6.5 \mathrm{~kg}$. In E.P. II most of the cows received $16-18 \mathrm{~kg}$ of warm Dutch silage; one cow alone received $10 \mathrm{~kg}$. The quantities of grass-meal now fluctuated between 3.8 and $9.4 \mathrm{~kg}$, with an average of $6.4 \mathrm{~kg}$.

The grass-meal administered in the two halves of the experimental period was not the same; that used in E.P. I contained $11.6 \% \mathrm{dcp}$ and had a SE of 49.3 , and that used in E.P. II had $8.4 \%$ dep and a SE of 46.6 , all in terms of the $\mathrm{dm}$. The feeding value of these lots of grass was, therefore, very disappointing. This is probably the main cause that it was not possible to give most of the animals in the experimental group the quantity of dcp and SE which they needed for production and self-maintenance purposes. On the other 
hand, the cows in the control group, which received $13 \mathrm{~kg}$ of hay + concentrates, were exactly fed to the standards.

The result was, therefore, a gradually increasing difference in live weight, in favour of the control group. The average difference per cow was at the end $16.7 \mathrm{~kg}$. However, in the second control period, when all cows were pastured together, this difference in weight completely disappeared.

No difference in condition was observed.

There was also a difference in production in favour of the control group; this difference averaged $0.53 \mathrm{~kg}$ of milk and $28.3 \mathrm{~g}$ of fat per animal per day.

The difference is not very great, especially not if the poor quality of the grass-meal is taken into consideration. It seems probable that, if a good quality grass-meal had been used, the results of feeding cattle on exclusively pasture products, without concentrates, would not have remained behind those of the control cows which received, besides $13 \mathrm{~kg}$ of hay, an average of $5.0 \mathrm{~kg}$ of concentrates per day in E.P. I, and $3.7 \mathrm{~kg}$ in E.P. II.

Furthermore, the iodine value of the butterfat of the experimental group was 8.7 units higher, which is a very definite advantage as regards winter butter. Moreover, the carotene and vitamin A content of the experimental group's butter was just as high as in the pasture-period, later on.

And finally, still two feeding trials were made at Hoorn, in which the experimental ration consisted of dried grass (Dijkstra, 1954).

In these trials artificially dried spring grass was compared with artificially dried autumn grass from the same field.

These trials were made on account of the opinion, voiced by a great many farmers, that, if dried grass is available which has been cut during the different seasons of the year, preference must nevertheless always be given to spring grass, even if analyses should show that it is not better than any other lot as regards SE and dcp-content.

Since, at the time of the first trial (1950) there was no drying plant in the neighbourhood of Hoorn, the trial was made with grass from Leeuwarden airfield, although we were fully aware that it might not be the ideal material for such a trial.

As the digestibility of the dried lots of grass was determined before commencement of the trial, care could be taken to ensure that the total SE supplied, to the one group of cows, in the form of $5 \mathrm{~kg}$ of dried spring grass, was practically equal to that supplied to the other group, in the form of autumn grass. Nor was there any substantial difference between the quantities of dep supplied in this way to both groups.

In this trial, it was impossible to discern any specific effect whatever in favour of the spring grass. There was practically no difference between both groups in live weight, condition or production.

Because the management and manuring of the grass on an airfield deviates much from that of a normal pasture, a second trial was taken in 1952 with grass from one of the best pastures of our experimental farm. The spring grass was cut at April 28 and the autumn grass at October 22. The grass was artificially dried in a new drying-plant that has been built in the last year in the vicinity of Hoorn.

In this trial too the quantity of $\mathrm{SE}$ and dep supplied to the one group of 
cows, in the form of $5 \mathrm{~kg}$ of dried spring grass, was practically equal to that supplied to the other group, in the form of $5 \mathrm{~kg}$ of dried autumn grass.

Also in this trial there was practically no difference between both groups in live weight, condition and in the production of milk, fat and solids-not-fat.

Consequently the conclusion can be, that there is no reason to suppose that the artificially dried spring grass has a more favourable effect than the autumn grass on live weight, condition and production of milking cows.

\section{Trials With gRass SILAGE}

In the foregoing pages an exposition has been given of the way in which at Hoorn formulas have been calculated by means of which the feeding value of hay, fresh and dried grass can be estimated as well as possible from the chemical composition.

Until recently, however, we have not ventured to calculate such formulas for grass silage, because this is rather more difficult, owing to the fact that there are various kinds of grass silage ; in the first place, warm and cold silages, and, as regards the latter, good and bad as well (Dijkstra, 1948, 1949).

In course of time the number of digestion trials with grass silage rose to such an extent that in each category a rather large number of samples had been examined for digestibility. A few years ago we had at our disposal the results of 12 digestion trials on grass silage prepared by the warm method, and of 34 on grass silage prepared by the cold method, with or without addition; of these 34, 16 had been completely good ( $\mathrm{pH}$ below 4.2), and 18 had been less good or bad.

Just as before, all percentages were converted into terms of the om, while, furthermore, in some cases the $\mathrm{pH}$ 's of the samples were also brought into the calculations.

In order to provide a better view of the relation between the dep- and cp-contents of the various types of grass silage, Fig. 5 has been drawn.

In this graph, $x=\mathrm{cp}$ of the various samples has been plotted on the horizontal axis, and $\mathrm{d}=\mathrm{dcp}$ has been plotted on the vertical axis, both in om.

The figures relating to "good cold silages" are represented by dots, those relating to "less good or bad cold silages" by circles, and those relating to "warm silages" by small crosses.

As can be seen from the graph, the dots lie higher than the circles, and the latter, in their turn, lie higher than the crosses. Both dots and circles lie nicely in a straight line. So there is a good relation here between $\mathrm{cp}$ - and dcp-content. This could be seen anyway from the very high correlation coefficients : 0.992 for the good cold silages, and 0.988 for the bad cold silages; in the case of the warm silages the relation was not so good (correlation coefficient $=0.763$ ).

A straight regression line was computed for each of the three categories. Since the regression coefficients differed but little from each other as regards the good and bad cold silages, one common regression coefficient was calculated for them, so that the regression lines for these two kinds run parallel.

In this way the following formulas were found:

good cold silages : $\mathrm{d}=1.043(\mathrm{x}-17)+11.19$,

bad cold silages : $\mathbf{d}=1.043(\mathrm{x}-17)+\mathbf{1 0 . 2 2}$,

warm silages : $\quad \mathrm{d}=1.198(\mathrm{x}-17)+8.63$. 
$\operatorname{dcp}(\mathscr{c})$ in om

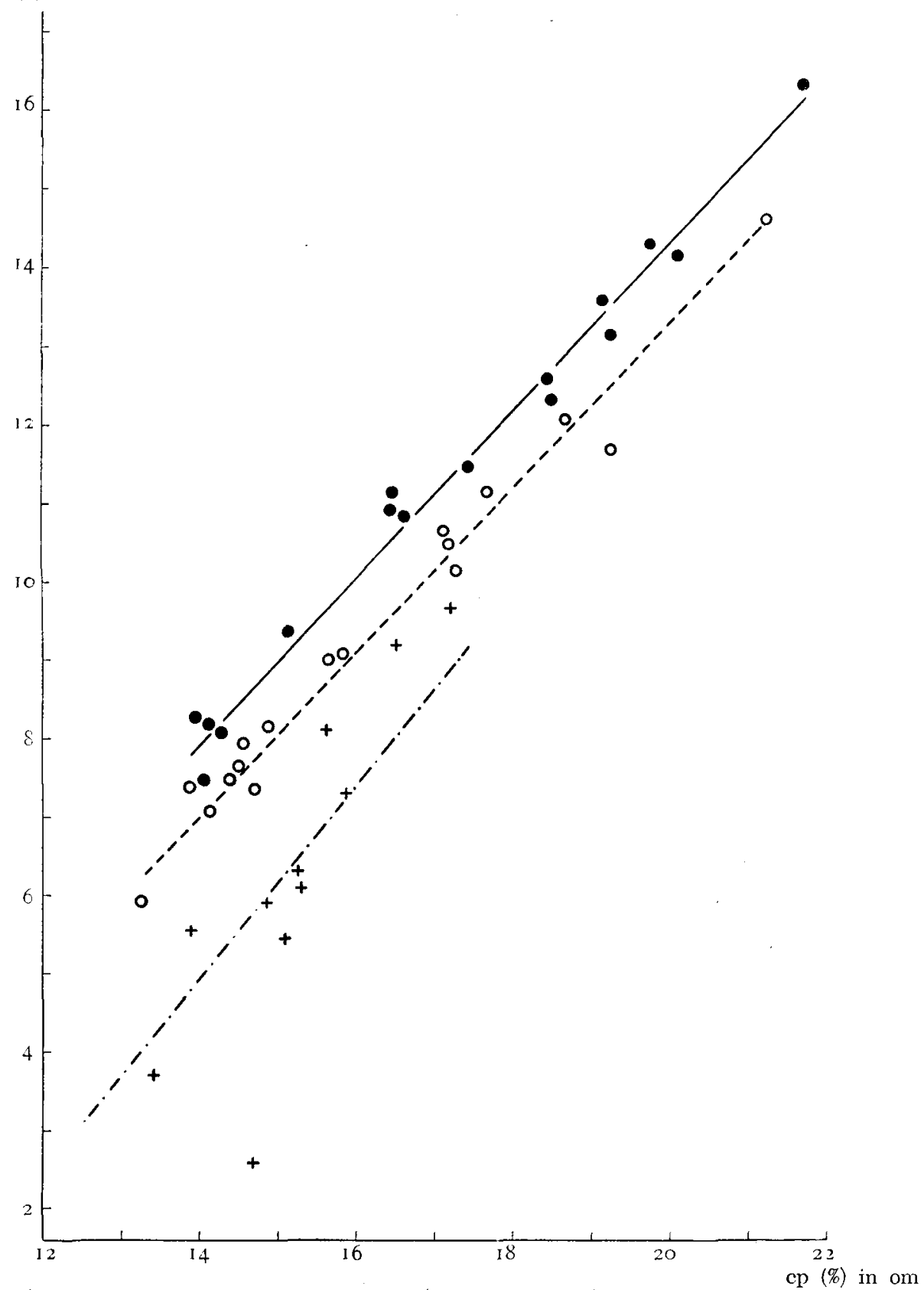

Fig. 5. RELATION BETWEen CRUDE PROTEIN (hORIZONTAL AXIS) AND DIGESTIBLE CRUDE PROTEIN (VERTICAL AXIS) IN 16 GOOD COLD GRASS SILAGES (DOTS), 18 LESS GOOD OR BAD COLD grass silages (CIRCles), aNd 12 Warm grass silages (Crosses).

When, for everyday use, these formulas are converted into terms of dry matter, the formulas become:

good cold silages: $\mathrm{d}^{\prime}=1.043\left(\mathrm{x}^{\prime}-15\right)+0.065\left(\mathrm{~m}^{\prime}-12\right)+9.89, \quad(8 \mathrm{a})$ bad cold silages: $d^{\prime}=1.043\left(x^{\prime}-15\right)+0.075\left(m^{\prime}-12\right)+9.04, \quad(9 a)$ warm silage

$\mathrm{d}^{\prime}=1.198\left(\mathrm{x}^{\prime}-15\right)+0.117\left(\mathrm{~m}^{\prime}-12\right)+7.65 . \quad(10 \mathrm{a})$ 
Although the average ash content (soil included) of the samples on which these calculations have been based was rather high (for good cold silages $12.6 \%$, for bad cold silages $14.8 \%$ and for warm silages $14.2 \%$ ), we have chosen an average ash-content of $12 \%$ in these formulas, because lower ash-contents (average $11 \%$ ) have generally been found at the C.I.L.O. In cases in which the ash-content is $12 \%$, or is not known, the term containing $\mathrm{m}^{\prime}$ is eliminated, and the first formula becomes:

$$
\mathrm{d}^{\prime}=1.043\left(\mathrm{x}^{\prime}-15\right)+9.89 \text {, etc. }
$$

As regards the $\mathrm{SE}$, attention was turned again in the first place to the content of dom.

In order to study the relation between the dom- and cf-contents of the different grass silages, they were plotted together in a graph.

Although there was a certain correlation between them, the scatter of the points was nevertheless very great, as also appeared from the size of the correlation coefficient. This was -0.524 for the cold grass silages - which were regarded as one group for the purpose - and -0.743 for the warm silages. Accordingly, the relation between the cf- and dom-contents was better in the warm silages than in the cold ones.

Furthermore, it was obvious that the relation between dom and $\mathrm{pH}$ ought also to be studied. With that intention, in Fig. 6 the $\mathrm{pH}$ has been plotted on the horizontal axis, and the percentage of dom in the om on the vertical axis. In this diagram the data relating to the good cold silages are represented by dots, and those relating to the less good and bad cold silages by small circles.

Since no relation was found between dom and $\mathrm{pH}$ in the warm silages, the figures relating to warm silages have been omitted.

The regression line drawn in Fig. 6 therefore relates only to the cold silages. The correlation coefficients also show that there is a rather good relation between the two quantities in the case of these cold silages, as opposed to that of the warm silages. In the cold silages the partial correlation with the cf was only a weak one, viz. -0.22 , and that with the $\mathrm{pH}$ quite considerable, i.e. -0.72 . It might therefore be possible to calculate a formula for the dom of cold silages in which only the $\mathrm{pH}$ occured. One was calculated, however, in which both the $\mathrm{pH}$ and the cf-content appeared, because the cf-content would have to be brought later anyway into the calculation to convert the dom into terms of SE. The formula becomes:

$$
\mathrm{z}=-0.271(\mathrm{y}-30)-4.726(\mathrm{p}-4.4)+69.31 \text {, }
$$

in which $\mathrm{p}=\mathrm{pH}$, and the other symbols have the same meaning as in the previous formulas.

In the warm silages, on the other hand, the partial correlation between of and dom was considerably better than between $\mathrm{pH}$ and dom, viz., -0.62 as compared with +0.32 . As, moreover, the partial correlation coefficient between $\mathrm{pH}$ and dom was found to be positive (i.e., the higher the $\mathrm{pH}$, the better the digestibility of the organic matter), the $\mathrm{pH}$ was left out of consideration in the study of warm silages, and a regression formula calculated in which the dom-content was only dependent from the cf-content:

$$
\mathrm{z}=-1.429(\mathrm{y}-30)+70.61 \text {. }
$$

The SE was computed again in the usual way:

$$
\mathrm{S}=\mathrm{dom}-0.06 \mathrm{dcp}-\text { "a certain factor" } \times \text { cf. }
$$




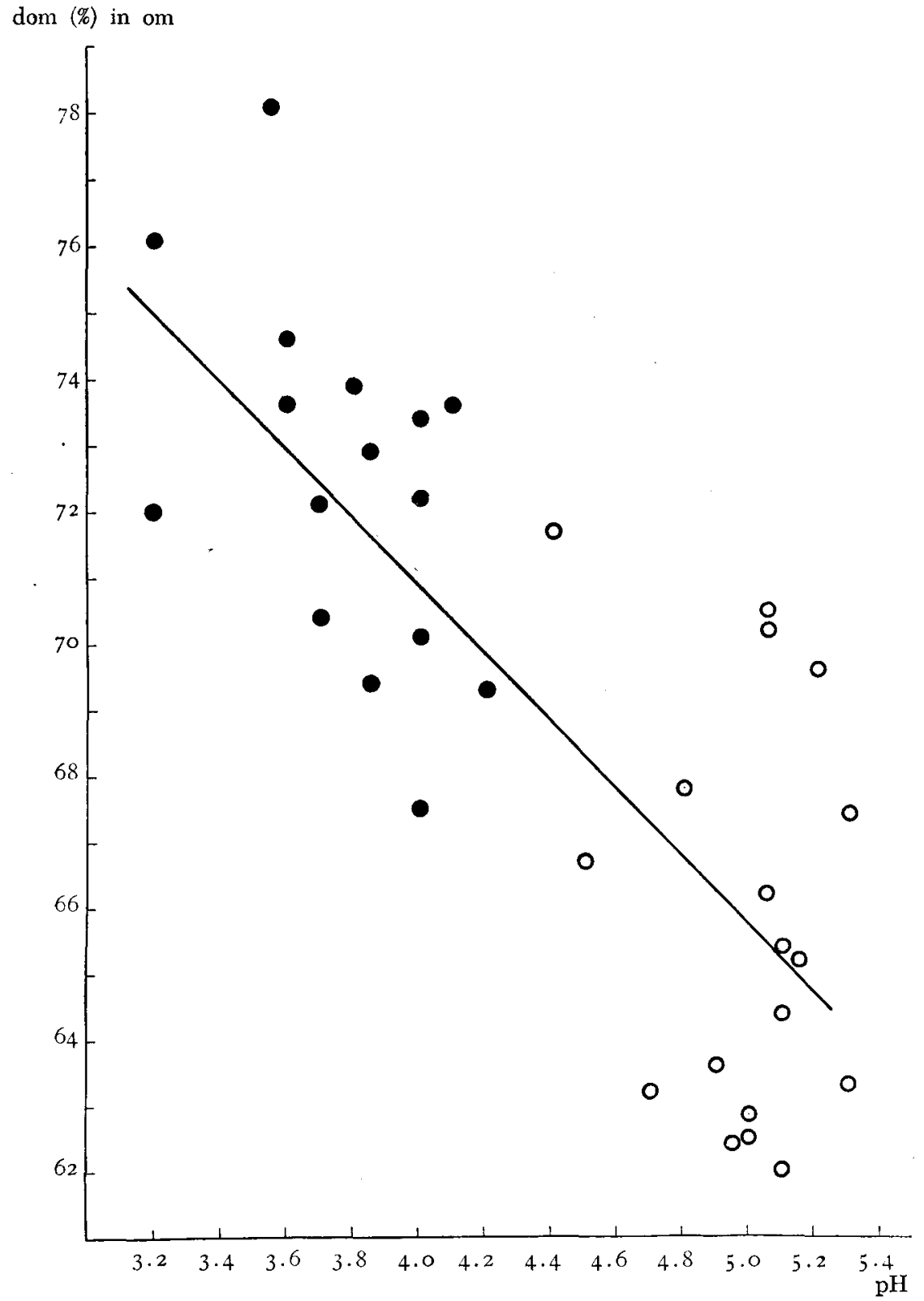

Fig. 6. Relation Between PH (horizontal axis) aND digestible organic Matter (vertical AXIS) IN 16 GOOD COLD GRASS SILAGES (DOTS) AND 18 LESS GOOD AND BAD COLD GRASS SILAGES (CIRCLES).

KELLNER says that this factor may fluctuate between 0.29 and 0.58 , all according to the cf-content of the fresh material. In the case of $4 \%$ of or less, the factor is 0.29 , and, as the cf-percentage rises, the factor also increases gradually, to reach 0.58 at $16 \%$ of or more.

Since the cold silages were found to possess an average cf-content of $5.6 \%$, an average cf-deduction factor of 0.33 was taken for them. 
The average cf-content of the warm silages was approximately $8.00 \%$, and consequently the factor there was 0.38 .

For the cold silages, the formula for the SE therefore becomes:

$$
\mathrm{S}=\mathrm{z}-0.06 \mathrm{~d}-0.33 \mathrm{y} \text {. }
$$

In order to eliminate $d$ from this formula, the relation between $d$ and $y$ was studied in all 64 samples.

Three parallel regression lines were calculated for the three groups : good cold silages, bad cold silages, and warm silages. In this way, the following result was found for the good cold silages :

$$
\mathrm{d}=-0.570(\mathrm{y}-30)+11.48 \text {. }
$$

The constant factor was 10.53 for the bad cold silages, and 8.04 for the warm silages.

For the cold silages, the following formula was taken for $0.06 \mathrm{~d}$ :

$$
0.06 \mathrm{~d}=-0.034(\mathrm{y}-30)+0.66 \text {. }
$$

In the good cold silages the constant term was 0.69 , and in the bad cold silages 0.63 ; but, since the difference was so slight, the average could be used.

With the aid of this equation we calculated:

$$
\mathrm{S}=-0.567(\mathrm{y}-30)-4.726(\mathrm{p}-4.4)+58.75
$$

The starch equivalent formula for the warm silages became:

$$
\mathrm{S}=\mathrm{z}-0.06 \mathrm{~d}-0.38 \mathrm{y} \text {. }
$$

In the case of these silages :

$$
0.06 \mathrm{~d}=-0.034(\mathrm{y}-30)+0.48 \text {. }
$$

If this is inserted into the equation for $S$, the result will be :

$$
\mathrm{S}=-\mathbf{1 . 7 7 5}(\mathrm{y}-\mathbf{3 0})+\mathbf{5 8 . 7 3} \text {. }
$$

These formulas for SE again, are converted into terms of $\mathrm{dm}$.

For cold grass silages the formula then becomes:

$$
S^{\prime}=\underset{\left(m^{\prime}-12\right)(0.047 \mathrm{p}-0.97)+51.36}{-0.567\left(y^{\prime}-27\right)+}
$$

and for the warm grass silages it is :

$$
S^{\prime}=-1.775\left(y^{\prime}-27\right)-1.120\left(m^{\prime}-12\right)+50.62
$$

In the course of years various feeding experiments with grass-silages have been made at Hoorn.

In the first experiments (Brouwer, 1926, 1927; 1927, 1928) the feeding value of grass-silage was compared with that of hay. The result of the experiment made in the winter 1925-'26 was that $100 \mathrm{~kg}$ of $\mathrm{dm}$ in silage (made by the warm Dutch clamp process) had about the same feeding value as $105 \mathrm{~kg}$ of $\mathrm{dm}$ in hay. In the experiment in the winter 1926-'27 the hay was of a less good quality as in the year before. Now $100 \mathrm{~kg}$ of $\mathrm{dm}$ in silage had the same feeding value as $120 \mathrm{~kg}$ of dry matter in hay.

In later experiments the feeding value of silages prepared by the warm method was compared with that of A.I.V.-silages (BROUWER, DE RUYTER DE WILDT, Holleman and Frens, 1932, 1933; Brouwer and Dijkstra, 1935, 1936). In the experiment in the winter 1932-33, the warm silage had a dcp-content of $4.8 \%$ and a SE of 47 and the A.I.V.-silage contained $10.8 \%$ dep and had a SE of 52. 
When this difference in feeding value was taken into consideration the production and live weight of the two groups were practically the same. In the experiment in the winter 1934-'35 the warm silage had a dcp-content of $7.3 \%$ and a $\mathrm{SE}$ of 54, whereas for the A.I.V.-silage these figures were $12.5 \%$ and 59 , respectively. Consequently the warm silage had to be completed with groundnut cake meal and the A.I.V.-silage with a small amount of barley meal. The milk and fat production of the group receiving A.I.V.-silage was somewhat higher than that of the warm-silage-group.

Further there was a feeding experiment (Dijкstra, 1948, 1949) with two groups of cows, which demonstrated that a silage made by the cold method without any addition had exactly the same feeding value as a silage made from the same grass with addition of Vitasan.

Finally there were still two experiments with A.I.V.-silage. In the first (DijkSTRA, 1947, 1949) the feeding value of $20 \mathrm{~kg}$ of A.I.V.-silage was compared with that of $8 \mathrm{~kg}$ of hay. There was practically no difference in milk and fat production. However, there was an important difference in the iodine value and carotene and vitamin A-content of the butter in favour of the silage group.

The last feeding experiment (Dijkstra, 1949) with A.I.V.-silage was owing to the Danish reports that the way in which the A.I.V.-silage will be neutralized has a great influence on its feeding value. Neutralizing with beets or beet pulp would give a much better result than with chemical products as chalk, bicarbonate or soda.

In our experiment we could not confirm the Danish suggestion. There was no difference between the two groups of milking cows in live weight, condition and milk and fat production.

In the last years the so-called wilted silages are more and more made in the Netherlands. If grass that has been wilted till at least $40 \%$ of dry matter, is brought quickly into a silo, the grass is well tramped and the silage is immediately covered with a very heavy soil layer, than the silage will be a success.

The number of digestion trials is still too small for calculating definitive regression formulas for dcp and $\mathrm{SE}$.

The provisional results show that the dcp-content in the om of good wilted silages lies between that of good and bad cold silages and that the following formula can be used till more data are available:

$$
\mathrm{d}=1.043(\mathrm{x}-17)+10.87
$$

in which $\mathrm{d}=\mathrm{dcp}$ and $\mathrm{x}=\mathrm{cp}$, both in om.

For dom our old formula for fresh grass is in rather good accordance with the results of the small number of trials :

$$
\mathrm{z}=82.36-0.287 \times 10^{0.0501 \mathrm{y},}
$$

in which $\mathrm{z}=$ dom and $\mathrm{y}=\mathrm{cf}$, both in om.

Provisionally, we have chosen the same factor for cf-deduction for wilted silages as for artificially dried grass, viz. a deduction of $0.44 \mathrm{~kg} \mathrm{SE}$ for each percent of cf. Consequently the provisional formula for SE will be:

$$
\mathrm{S}=80.23-0.391 \mathrm{y}-0.287 \times 10^{0.0501 \mathrm{y}}
$$

As soon as a sufficient number of digestion trials has been made with wilted 296 
silages, better and more definitive regression formulas will be calculated for dcp and SE in this kind of silages.

\section{LITERATURE}

V.L.O. = Verslagen landbouwkundige Onderzoekingen.

J.P. $\quad=$ Jaarverslag Proefzuivelboerderij te Hoorn.

BRouwer, E. : V.L.O. 32 (1927) 69-171; J.P. (1926) 41-143.

- - : V.L.O. 33 (1928) 10-75; J.P. (1927) 1-67.

- -, J. C. de Ruyter de Wildt, L. W. J. Holleman and A. M. Frens : V.L.O. 39 (1933) 401-463; J.P. (1932) 135-197.

- - and N. D. Dijkstra : V.L.O. 42 (1936) 291-333; J.P. (1935) 143-185.

- -, - - : V.L.O. 44 (1938) 529-612; J.P. (1938) 7-90.

,---- : V.L.O. 45 (1939) 119-147; J.P. (1938) 177-205.

- - , - - : V.L.O. 45 (1939) 763-805; J.P. (1939) 157-199.

- -, - - : V.L.O. 47 (1941) 1275-1298; J.P. (1941) 83-106.

Dijkstra, N. D. and E. Brouwer : V.L.O. 45 (1939) 1-45; J.P. (1938) 107-151.

- - : V.L.O. 45 (1939) 617-648; J.P. (1939) 95-126.

- - : V.L.O. 49 (1943) 29-63; J.P. (1942) 63-97.

- - : V.L.O. 54.11 (1949) 1-48; J.P. (1947) 54.11, 1-48.

- - : V.L.O. 55.3 (1949) 1-53; J.P. (1948) 55.3, 1-53.

- - : V.L.O. 54.9 (1949) 1-51; J.P. (1947) 54.9, 1-51.

- - : V.L.O. 55.10 (1949) 1-15; J.P. (1948) 55.10, $1-15$.

- - : V.L.O. 57.1 (1949) 1-30; J.P. (1949) 57.1, 1-30.

- - : The influence of artificial drying on the digestibility of grass. Report on the VIIIth Intern. Congress of Agr. Ind., Brussels, 1950.

- - : V.L.O. 60.1 (1954) 1-42.

Frederiksen, Lars and P. S. ØstergaArd: 136de Beretning fra Fors $\phi g s l a b$., København, 1931.

KeLLnER, O.: Grundzüge der Fütterungslehre. Paul Parey, Berlin. 